\title{
Steroid Withdrawal related Relapse in a Patient with Neuro-Behçet's Disease
}

\author{
Steroid Tedavisinin Kesilmesine Bağlı Nöro-Behçet Atağı
}

Bekir Enes Demiryürek

Sakarya Training and Research Hospital, Clinic of Neurology, Sakarya, Turkey

Keywords: Neuro-Behçet, steroid, attack

Anahtar Kelimeler: Nöro-Behçet, steroid, atak

\section{Introduction}

A woman aged 40 years who had been followed-up and treated for neuro-Behçet's disease (NBD) with parenchymal involvement for nine years, presented to our clinic with symptoms of speech impairment, ocular deviation, diplopia, and blurred vision, which she had had for one day. She had no headache, nausea or vomiting. Her medical history revealed no diseases other than NBD. The patient was on etanercept $50 \mathrm{mg} /$ week and colchicine $0.5 \mathrm{mg} /$ day treatment for her NBD. She had been free of relapses for seven years and her steroid treatment had been tapered off. Steroid treatment consisting of deflazacort 6 $\mathrm{mg} /$ day had eventually been discontinued one month ago at another institution due to the development of osteopenia and the seven-year remission. Her neurologic examination revealed medial deviation of both eyes in the primary gaze and bilateral lateral gaze palsy. There was no motor or sensory deficits however, the left upper extremity was dysmetric. Involuntary episodes of laughter and crying had also emerged. Brain magnetic resonance imaging (MRI) was suggestive of neuro-Behçet's relapse with diffuse hyperintense involvement in the brain stem on axial fluid-attenuated inversion recovery (FLAIR) images (Figure 1A, 1B, 1C), and punctate contrast enhancement in an axial T1 sequence (Figure 1D). Pulse steroid therapy was administered for ten days. Following treatment, the medial gaze palsy initially observed in the primary position was improved. Bilateral lateral gaze palsy had also partially improved. Dysmetria disappeared; however, pseudobulbar signs persisted. The patient's brain MRI revealed that the hyperintense involvement was reduced in the pons and mesencephalon in axial FLAIR images compared with the presteroid MRI (Figure 2A, 2B), and there was no bulbar involvement (Figure 2C). The patient continues to be followed up at our clinic and cyclophosphamide treatment was planned.

NBD has a severe clinical picture with high morbidity and mortality rates, despite being a rare complication of Behçet's disease (1).

The use of systemic steroids in the treatment of NBD are known to be effective in preventing relapse and stopping clinical progression. However, there have been reports of patients in whom steroid therapy could not be discontinued due to frequent relapses and/or fluctuations (2).

Steroid maintenance therapy at reduced dosages appears to be worthwhile in the treatment of NBD, considering the re-emergence of relapse symptoms and a dramatic brain stem involvement in our patient following discontinuation of low-dose steroid therapy, despite a relapse-free period for seven years.

\section{Ethics}

Peer-review: Internally peer-reviewed.

\section{References}

1. Yoon DL, Kim YJ, Koo BS, Kim YG, Lee CK, Yoo B. Neuro-behcet's disease in South Korea: clinical characteristics and treatment response. Int J Rheum Dis 2014;17:453-458.

2. Inaba G. Behçet's disease in: Vinken PJ, Bruyn GW, Klawans HL, eds. Handbook of clinical neurology. Elsevier: Amsterdam 1989;56:593-610.

Address for Correspondence/Yazışma Adresi: Bekir Enes Demiryürek MD, Sakarya Training and Research Hospital, Clinic of Neurology, Sakarya, Turkey Phone: +905335508872 E-mail: bekirenes@mynet.com

Received/Geliş Tarihi: 31.01 .2016 Accepted/Kabul Tarihi: 20.03 .2016

${ }^{\circledR}$ Copyright 2016 by Turkish Neurological Society

Turkish Journal of Neurology published by Galenos Yayınevi. 

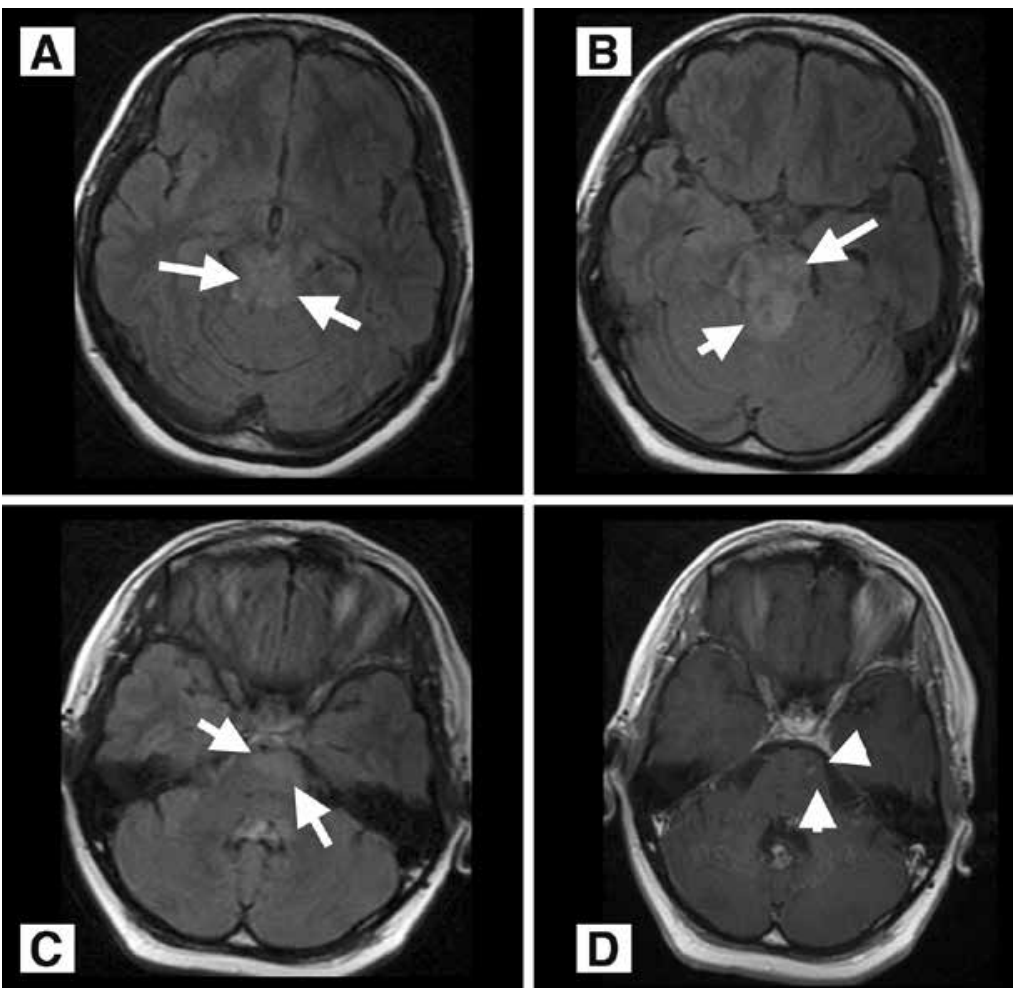

Figure 1. Hyperintense lesions in flair sequences in mesencephalon (A), pons (B) and bulbus (C) at presentation. Punctate enhancement can be seen in the pons (D).
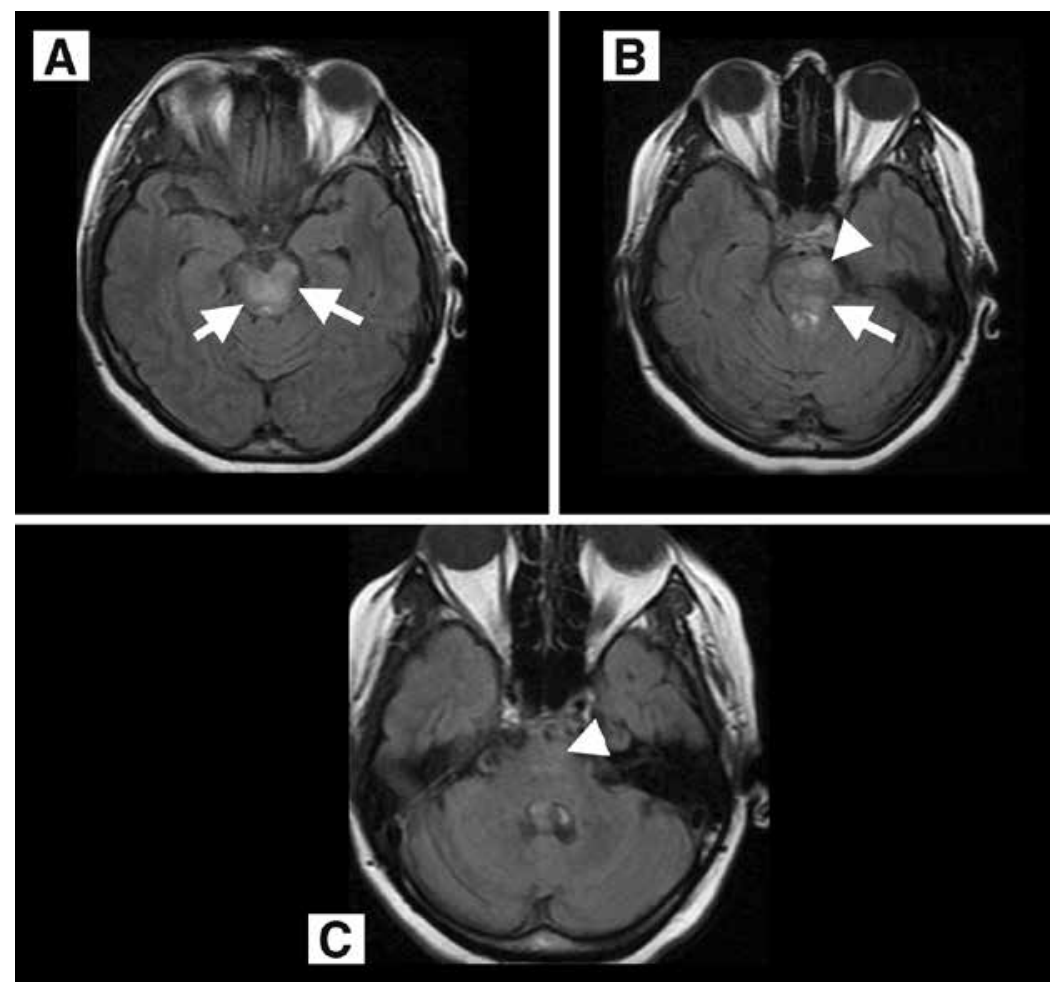

Figure 2. The size of the lesions seen in mesencephalon (A) and pons (B) is reduced compared to Figure 1, while dissappeared in the bulbus (C) in axial FLAIR of magnetic resonance imaging obtained after 10-day pulse steroid (prednisolone $1000 \mathrm{mg} /$ day) treatment. 